\title{
CONCENTRAÇÃO DE CÁTIONS PRESENTES NO LIXIVIADO DE SOLOS TRATADOS COM VINHAÇA
}

\section{FÁBIO L. BRITO ${ }^{1}$, MÁRIO M. ROLIM², ELVIRA M. R. PEDROSA ${ }^{2}$}

RESUMO: O presente estudo teve como objetivo avaliar a qualidade do lixiviado de solos que receberam doses de vinhaça em diferentes tempos de incubação. Para isso, em 27 colunas de PVC de $20 \times 110 \mathrm{~cm}$ (diâmetro x altura), foram reproduzidos três solos classificados como Nitossolo Háplico, Argissolo Amarelo e Espodossolo Cárbico, com horizontes, espessuras e densidades semelhantes à original. Os solos foram tratados com vinhaça em doses equivalentes a 0 (testemunha), 350 e $700 \mathrm{~m}^{3} \mathrm{ha}^{-1}$ e submetidos aos tempos de incubação de 30 e 60 dias. Nos efluentes coletados, foi realizada análise de $\mathrm{K}, \mathrm{Ca}, \mathrm{Mg}$ e $\mathrm{Na}$, e os dados obtidos, submetidos à análise multivariada, a 5\% de probabilidade. Os resultados indicaram efeito significativo para as variáveis $\mathrm{K}, \mathrm{Ca}, \mathrm{Mg}$ e $\mathrm{Na}$ com respeito ao solo, dose e tempo de incubação, exceto o Na para a causa de variação solo. De maneira geral, os menores valores das concentrações de cátions presentes nos lixiviados foram obtidos no Nitossolo, maior fração argila, seguido do Espodossolo devido ao horizonte espódico. Os valores dos cátions do lixiviado, comparados com os presentes na vinhaça in natura, foram significativamente reduzidos, indicando que os solos tiveram elevado poder de retenção.

PALAVRAS-CHAVE: resíduo, elementos químicos, percolado.

\section{CÁTIONS CONCENTRATION IN LEACHATE FROM SOILS TREATED WITH VINASSE}

\begin{abstract}
The present study had the objective of evaluating leachate quality from soils that received different vinasse doses and incubation time. In twenty-seven $20 \times 110 \mathrm{~cm}$ (diameter $\times$ height) PVC columns, three soils, classified as Haplic Nitosol, Yellow Argisol and Carbic Spodosol, were reproduced with horizons, thickness and densities similar to original. The soils were treated with vinasse in doses equivalent to 0 (control), 350 and $700 \mathrm{~m}^{3} \mathrm{ha}^{-1}$ and submitted to incubation time of 30 and 60 days. Collected effluents were analyzed for $\mathrm{K}, \mathrm{Ca}, \mathrm{Mg}$ and $\mathrm{Na}$ contents, and data evaluated by multivariate statistical analysis, at 5\% level. The results pointed out significant effect for $\mathrm{K}, \mathrm{Ca}, \mathrm{Mg}$ and $\mathrm{Na}$ with regard to soil, dose and incubation time, except for $\mathrm{Na}$ in relation to soil. The lowest values for cation concentrations in the leachate were obtained for Nitosol which presented the highest clay fraction, followed by Spodosol due to the spodic horizon. When compared to vinasse in nature, leachate cation concentrations were significantly reduced indicating high retention power of the soils.
\end{abstract}

KEYWORDS: vinasse, leachate, soil.

\footnotetext{
${ }^{1}$ Engo ${ }^{\circ}$ Agrônomo, UFRPE/DTR, Rua Dom Manoel de Medeiros, s/n, Dois Irmãos, Recife - PE, Fone: (0XX81) $3320-6276$

${ }^{2}$ Prof. Adjunto, Departamento de Tecnologia Rural, UFRPE, Recife - PE, rolim@dtr.ufrpe.br, elvira.pedrosa@dtr.ufrpe.br Recebido pelo Conselho Editorial em: 5-10-2005

Aprovado pelo Conselho Editorial em: 17-9-2007
} 


\section{INTRODUÇÃO}

A vinhaça é conhecida como principal resíduo da indústria sucroalcooleira, principalmente pelo elevado volume gerado durante o processo de produção do álcool. Com o lançamento do Programa Proálcool na década de 1980, o consumo desse combustível automotivo aumentou consideravelmente e, paralelamente, o volume de vinhaça gerado. Pesquisas (ALMEIDA et al., 1952; RANZANI, 1956; CORREA et al., 2001; PAULINO et al., 2002; BRITO \& ROLIM, 2005) envolvendo o aproveitamento da vinhaça foram desenvolvidas, na maioria concluídas com sucesso, quanto ao aproveitamento do resíduo na fertirrigação de áreas plantadas com cana-de-açúcar, matéria-prima para a fabricação do álcool.

No entanto, CAMBUIM (1983) estudou o efeito da aplicação de três doses de vinhaça (0; 200 e $400 \mathrm{~m}^{3} \mathrm{ha}^{-1}$ ) no lixiviado, em diferentes tempos de incubação, encontrando diferenças significativas na concentração de cálcio, magnésio e potássio, comparados ao lixiviado da testemunha, que só recebeu água. No caso específico da concentração de potássio, na dose $200 \mathrm{~m}^{3}$ $\mathrm{ha}^{-1}$, não ocorreram diferenças no tempo de 0 e 20 dias, elevando-se aos 40 dias de incubação.

No mesmo contexto, em área de 12 ha fertirrigada com vinhaça, onde foram instalados 30 poços de monitoramento à profundidade de $3 \mathrm{~m}$, LYRA (2002) avaliou as concentrações dos íons potássio, cálcio e magnésio no lixiviado. Para o potássio, ficou evidenciado que os solos estudados foram eficientes na remoção do elemento, visto que os teores no lixiviado foram significativamente menores que os na vinhaça in natura.

O objetivo deste trabalho foi avaliar o poder de retenção de diferentes solos que receberam doses de vinhaça, no que diz respeito a íons lixiviados presentes na vinhaça que possam vir a poluir as águas do lençol freático.

\section{MATERIAL E MÉTODOS}

O experimento foi conduzido no Laboratório de Mecânica dos Solos e Aproveitamento de Resíduos, enquanto as análises químicas e físicas foram realizadas nos Laboratórios de Química do Solo, Fertilidade do Solo e de Física do Solo, da Universidade Federal Rural de Pernambuco UFRPE. A vinhaça utilizada foi fornecida pela Usina Petribu, Lagoa de Itaenga - PE, coletada no canal de distribuição, e sua caracterização físico-química encontra-se na Tabela 1.

Foram utilizados três tipos de solo representativos da zona da mata canavieira do Estado de Pernambuco, classificados de acordo com EMBRAPA (1999) como Nitossolo Háplico Eutrófico típico textura argilosa, coletado no Engenho Vazante, Aliança - PE; Argissolo Amarelo Distrófico fragipânico, textura média/argilosa, coletado no Sítio Santa Luzia, Aliança - PE, e Espodossolo Cárbico Órtico duripânico arênico de textura arenosa, proveniente da Unidade de Execução de Pesquisa de Itapirema, Goiana - PE. Na Tabela 2, encontram-se os resultados da análise química e a caracterização física, respectivamente.

TABELA 1. Caracterização físico-química da vinhaça in natura utilizada.

\begin{tabular}{ccc}
\hline Variáveis & Unidade & Valor \\
\hline $\mathrm{pH}$ & - & 4,4 \\
DBO $^{*}$ & $\mathrm{mg} \mathrm{L}^{-1}$ & 5.000 \\
DQO $^{*}$ & $\mathrm{mg} \mathrm{L}^{-1}$ & 26.771 \\
$\mathrm{CE}^{*}$ & $\mathrm{dS} \mathrm{m}^{-1}$ & 11,50 \\
$\mathrm{SDT}^{*}$ & $\mathrm{mg} \mathrm{L}^{-1}$ & 11.352 \\
$\mathrm{~K}$ & $\mathrm{mg} \mathrm{L}^{-1}$ & 1.123 \\
$\mathrm{Ca}$ & $\mathrm{mg} \mathrm{L}^{-1}$ & 352 \\
$\mathrm{Mg}$ & $\mathrm{mg} \mathrm{L}^{-1}$ & 16 \\
$\mathrm{Na}$ & $\mathrm{mg} \mathrm{L}^{-1}$ & 113 \\
\hline
\end{tabular}

*DQO - demanda química de oxigênio; DBO - demanda bioquímica de oxigênio; CE - condutividade elétrica; SDT sólidos dissolvidos totais. 
TABELA 2. Resultado da análise química e caracterização física dos diversos horizontes dos solos utilizados.

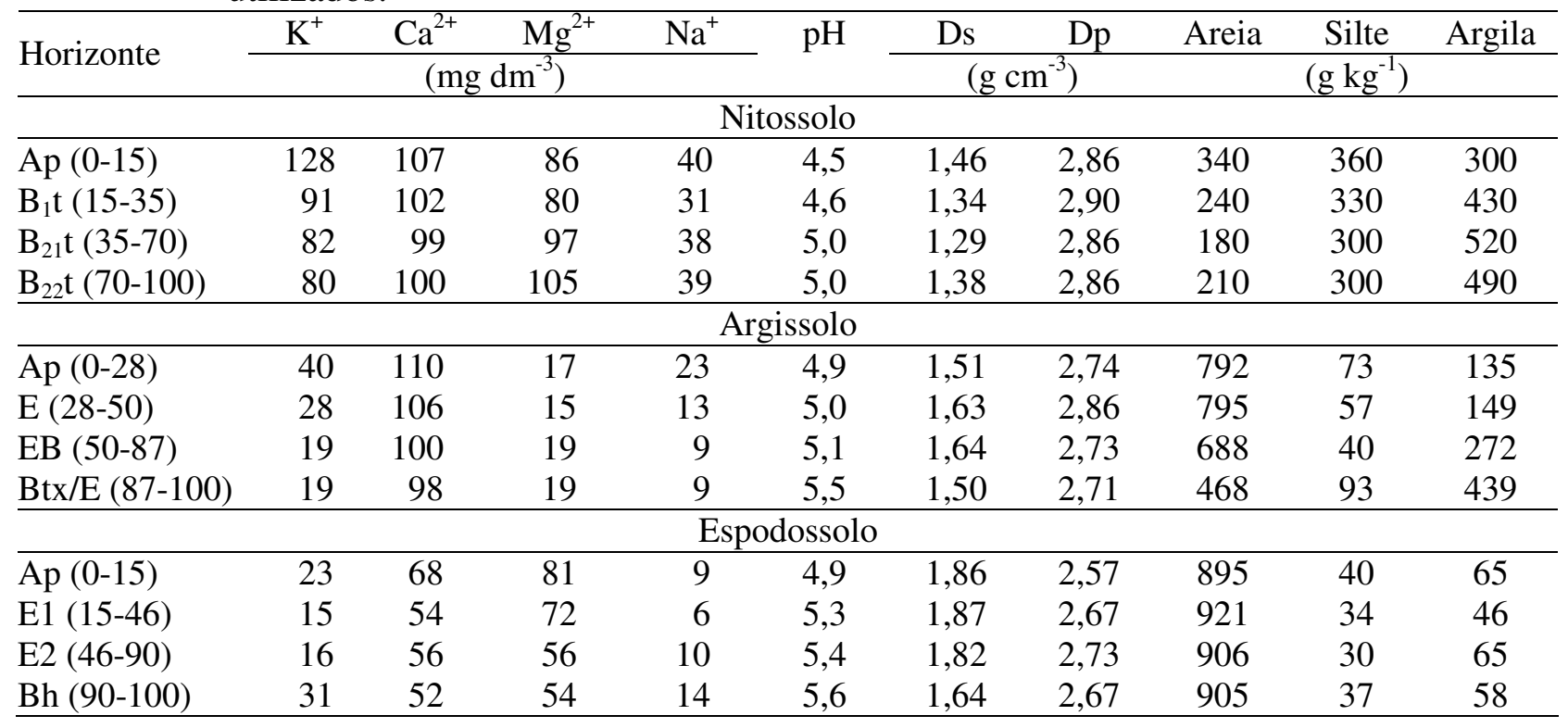

O experimento foi conduzido em 27 colunas de PVC de $20 \times 110 \mathrm{~cm}$ (diâmetro e altura, respectivamente), onde foram reproduzidos os três solos, respeitando-se altura e densidade dos respectivos horizontes até a profundidade de $100 \mathrm{~cm}$ (Figura 1). Posteriormente, as colunas foram saturadas por meio da ascensão da água pela parte inferior sob pressão constante, e liberados os drenos, mesmo local por onde se deu a saturação, permitindo-se a percolação da água até seu estancamento, ou seja, levadas à sua máxima capacidade de retenção de água contra a ação da gravidade (CAMBUIM, 1983).

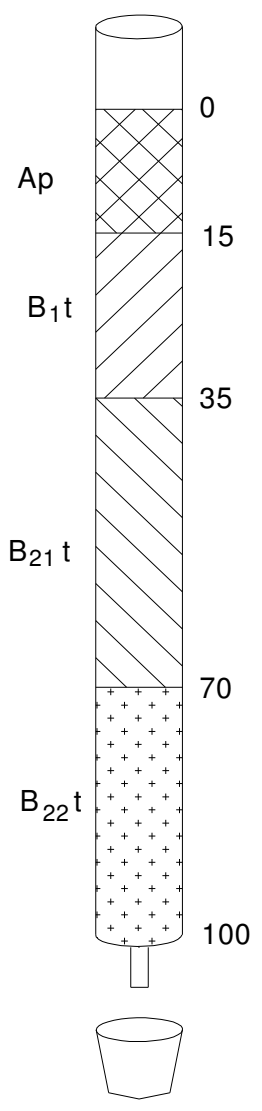

Nitossolo

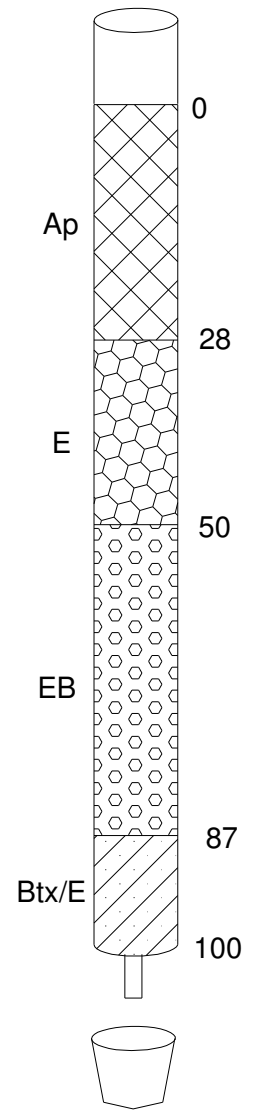

Argissolo

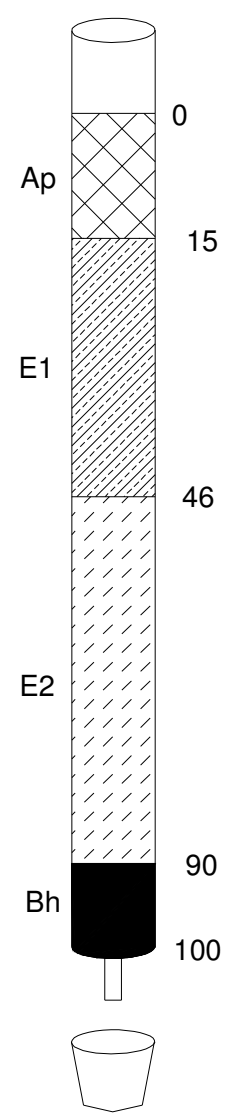

Espodossolo

FIGURA 1. Detalhe das colunas com os referidos horizontes, espessura e ponto de coleta do Nitossolo, Argissolo e Espodossolo, respectivamente (medidas em $\mathrm{cm}$ ). 
Após serem levados à capacidade de campo, os solos foram irrigados com doses equivalentes a 0, água, testemunha (Test), 350 (Trat. 1) e 750 (Trat. 2) $\mathrm{m}^{3} \mathrm{ha}^{-1}$ de vinhaça; os três tratamentos foram conduzidos com três repetições, totalizando 27 colunas, nove para cada tipo de solo. As coletas dos efluentes deram-se aos 30 e 60 dias de incubação, após a aplicação das doses de vinhaça; para isso, foi aplicada uma lâmina de lixiviação (água) equivalente ao volume de poros de cada solo, com a instalação de recipiente sob cada coluna. Nos dois tempos de incubação, as coletas davam-se na mesma coluna, ou seja, o lixiviado foi retirado de uma só coluna por duas vezes.

No que diz respeito ao sódio $(\mathrm{Na})$ e ao potássio $(\mathrm{K})$, as amostras foram analisadas pelo método da fotometria de chama; o cálcio (Ca) e o magnésio ( $\mathrm{Mg}$ ), determinados em espectrofotômetro de absorção atômica, todas segundo metodologia da EMBRAPA (1997).

$\mathrm{O}$ delineamento experimental utilizado foi inteiramente casualizado. Os tratamentos foram distribuídos em arranjo fatorial: três (tipos de solo: Espodossolo Cárbico Órtico, Nitossolo Háplico Eutrófico e Argissolo Amarelo Distrófico) versus três (doses de aplicação de vinhaça: 0; 350 e $700 \mathrm{~m}^{3} \mathrm{ha}^{-1}$ ), com medidas repetidas ao longo do tempo (30 e 60 dias), conduzidas com três repetições. Para a análise estatística dos dados, foi aplicado o teste de esfericidade de Mauchly (XAVIER, 2000) para a definição do tipo de análise a ser utilizada: univariada, caracterizada pela independência das duas medidas ao longo do tempo, ou multivariada, em que se considera a nãoindependência entre as medidas. Utilizou-se o "software" estatístico SAS (Statistical Analysis System), com níveis de significância de 5\%, para o teste F, sendo as médias comparadas pelo teste de Tukey, a 5\% de significância.

\section{RESULTADOS E DISCUSSÃO}

O teste de esfericidade de Mauchly indicou, para o presente estudo, o uso de análise multivariada de medidas repetidas, para todas as variáveis estudadas.

A análise multivariada, a 5\% de probabilidade, aplicada à variável $\mathrm{K}$ foi significativa para $\mathrm{o}$ efeito do solo, dose, tempo e para a interação tempo $\times$ dose, mas não para as demais interações (tempo $\times$ solo e tempo $\times$ solo $\times$ dose). Incrementos significativos $(P \leq 0,05)$ na concentração de $\mathrm{K}$, no lixiviado, em relação à testemunha ocorreram no Espodossolo e Argissolo, aos 60 dias, mas não aos 30 dias após a aplicação da vinhaça, para a dose 700 e $350 \mathrm{~m}^{3} \mathrm{ha}^{-1}$, que não diferiram entre si, e superiores à Testemunha (Figura 2, A e B).

A concentração de K (Figura 2, A) encontrada no lixiviado do Nitossolo foi de 4,38 $\mathrm{mg} \mathrm{L}^{-1}$ para o Trat. 1, menor dosagem, e 5,39 para a maior (Trat. 2), mostrando que grande parte do potássio adicionado via fertirrigação presente na vinhaça ficou retido no perfil, seja na fase trocável seja na fase solúvel do solo, corroborando CAMARGO et al. (1983) que observaram que a elevação da concentração de potássio no solo que recebeu vinhaça, foi extremamente maior que a elevação dos outros elementos.

Com relação à granulometria do solo, a análise estatística confirmou que, tanto aos 30 quanto aos 60 dias de incubação, os valores das concentrações de potássio do lixiviado, independentemente da dose aplicada, foram crescentes para o Espodossolo, Argissolo e Nitossolo, o que reforça a afirmação de SENGIK et al. (1988), de que as alterações do lixiviado dependem das características do solo.

As concentrações de $\mathrm{K}$, que foram de 9,21 e 16,00 para a menor dose, 10,15 e 21,54 mg L $\mathrm{L}^{-1}$ para maior dose no Argissolo e Espodossolo, respectivamente, aos 30 dias, podem ser consideradas baixas, demonstrando que, apesar da textura arenosa/argilosa e arenosa do Argissolo e do Espodossolo, respectivamente, os solos tiveram bom desempenho como redutores dos elementos analisados em comparação com os existentes na vinhaça in natura, corroborando BRITO et al. (2003). 


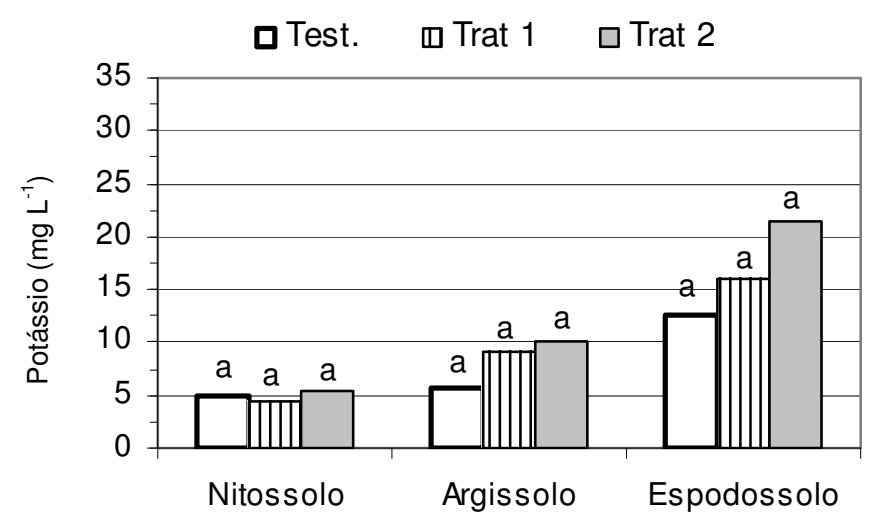

(A)

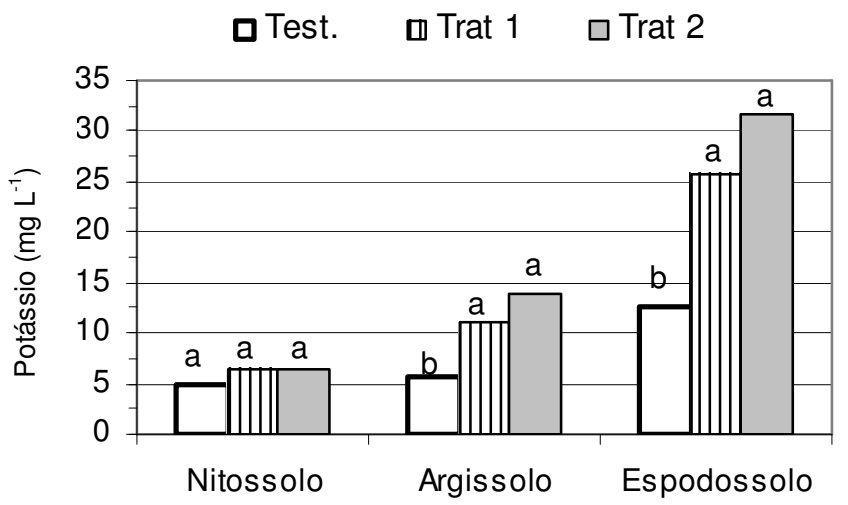

(B)

FIGURA 2. Concentração de K no lixiviado das colunas dos três tipos de solo, aos 30 (A) e 60 (B) dias após a aplicação de vinhaça; médias de três repetições, seguidas de mesma letra, não diferem pelo teste de Tukey, a 5\% de probabilidade.

Com relação à concentração de Ca no lixiviado, a análise multivariada a 5\% de probabilidade indicou efeitos significativos em relação ao solo, dose, tempo e suas interações. Aos 30 dias de incubação (Figura $3 \mathrm{~A}$ ), incrementos $(P \leq 0,05)$ nos valores de $\mathrm{Ca}$ decorrentes da aplicação de vinhaça (Trat. 2 e Trat. 1) ocorreram no Argissolo. Essas diferenças não se verificaram nos demais solos. Aos 60 dias (Figura 3 B), a concentração de Ca no lixiviado das colunas que receberam vinhaça, não diferiram da testemunha, exceto o Trat. 1 , no Nitossolo.

A concentração de Ca para o Nitossolo teve comportamento esperado, tendo em vista o maior percentual de argila; em contrapartida, o Espodossolo, bastante arenoso, comportou-se semelhantemente. Esse comportamento pode ser explicado pela presença do horizonte espódico, de acúmulo de matéria orgânica, que pode ter sido responsável pela maior adsorção desse elemento. No caso específico do Espodossolo, resultados semelhantes foram encontrados por BRITO et al. (2003).

O fato de o lixiviado dos três solos sofrer diminuição nos valores da concentração de Ca aos 60 dias pode ser explicado por parte do elemento ter sido lixiviado na primeira lâmina (30 dias) de lixiviação aplicada.

Tanto aos 30 quanto aos 60 dias, o lixiviado do Argissolo apresentou teores de $\mathrm{Ca}$ significativamente maiores que os encontrados nos demais solos, independentemente da dose aplicada, demonstrando que, para esse elemento, o solo mostrou-se menos eficiente que os demais com respeito à retenção, indicando que as respostas nos lixiviados dependem diretamente das características do solo (SENGIK et al., 1988). 
口Test. $\quad \mathbf{T}$ Trat $1 \quad \square$ Trat 2

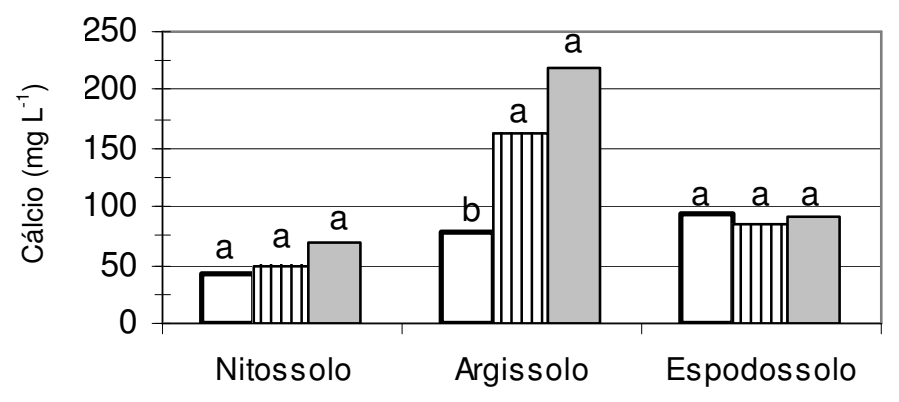

(A)

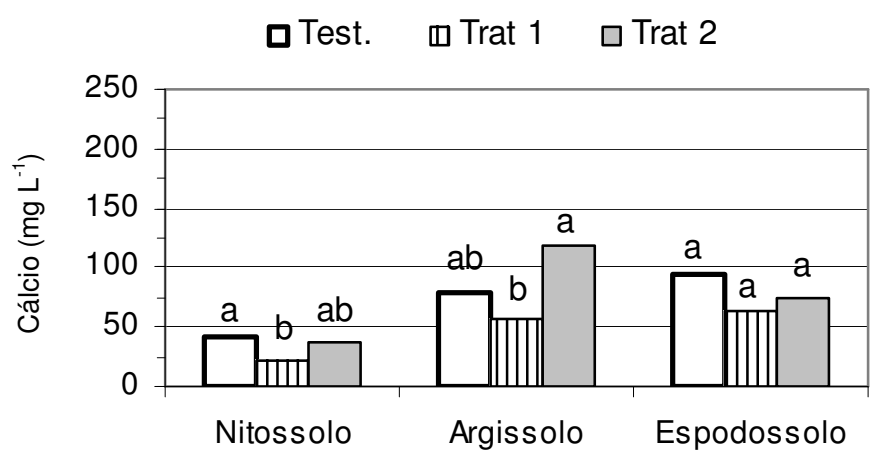

(B)

FIGURA 3. Concentração de Ca no lixiviado das colunas dos três tipos de solo, aos 30 (A) e 60 (B) dias após a aplicação de vinhaça; médias de três repetições, seguidas de mesma letra, não diferem pelo teste de Tukey, a 5\% de probabilidade.

A menor eficiência do Argissolo na adsorção do Ca pode ser em resposta ao seu pequeno teor de argila comparado com o Nitossolo e, no caso especial do Espodossolo, mesmo sendo mais arenoso, a presença do horizonte de acúmulo de matéria orgânica (horizonte espódico) conferiu a maior retenção do elemento. No entanto, aos 60 dias, o Argissolo e o Espodossolo tiveram comportamentos semelhantes em relação à concentração de Ca no lixiviado. Porém esses valores podem ser considerados baixos, comparados aos teores de $\mathrm{Ca}$ presentes na vinhaça in natura, demonstrando que os solos foram eficientes na retenção desse elemento, corroborando o observado por LYRA (2002).

A análise multivariada, a $5 \%$ de probabilidade, aplicada à variável $\mathrm{Mg}$ apresentou significância para o efeito do solo, dose, tempo e para as interacções tempo $\times$ solo e tempo $\times$ dose, mas não para as demais interações (solo $\times$ dose e tempo $\times$ solo $\times$ dose). Os teores de $\mathrm{Mg}$ encontrados nos lixiviados do Trat. 1 e do Trat. 2, aos 30 dias (Figura 4 A) foram significativamente maiores que os das testemunhas nos três tipos de solo. Aos 60 dias (Figura 4 B), as concentrações de $\mathrm{Mg}$ dos lixiviados do Trat. 1 e do Trat. 2 foram semelhantes à Test, exceto $\mathrm{o}$ Trat. 2 no Argissolo, uma vez que parte do elemento já havia sido perdida na primeira lâmina de lixiviação, corroborando BRITO et al. (2003).

A análise da interação tempo $\times$ solo indicou que, aos 30 dias, as maiores $(P \leq 0,05)$ concentrações de Mg no lixiviado ocorreram no Espodossolo, seguido do Argissolo e do Nitossolo, iguais entre si. Aos 60 dias de incubação, os maiores valores foram obtidos no lixiviado do Espodossolo e do Argissolo, iguais entre si, seguido do Nitossolo. Em todos os casos estudados, os valores encontrados na concentração de $\mathrm{Mg}$ foram pequenos, o que se evidencia pelos teores de $\mathrm{Mg}$ nos solos estudados e, principalmente, na vinhaça utilizada. 


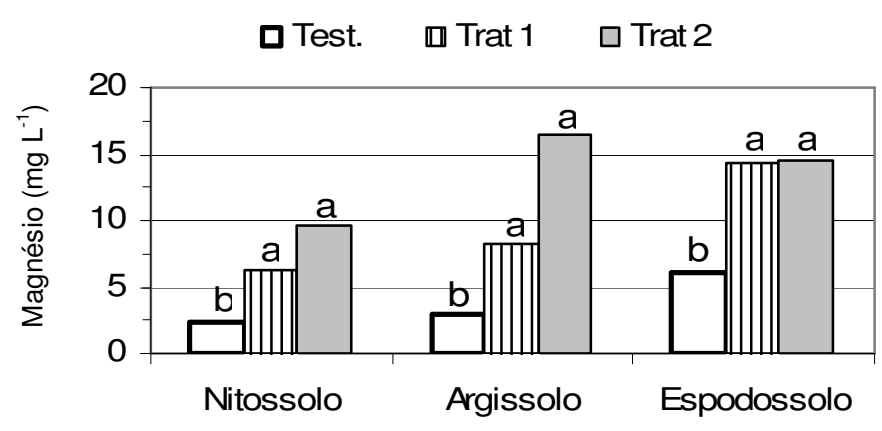

(A)

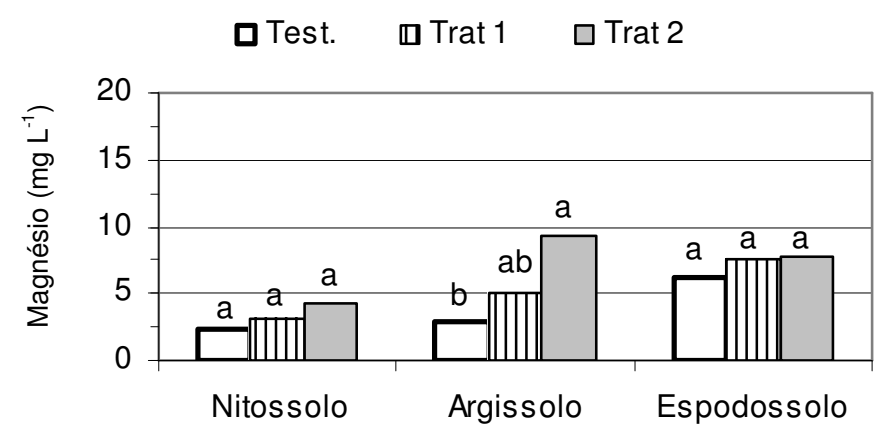

(B)

FIGURA 4. Concentração de Mg no lixiviado das colunas dos três tipos de solo, aos 30 (A) e 60 (B) dias após a aplicação de vinhaça; médias de três repetições seguidas de mesma letra, não diferem pelo teste de Tukey, a 5\% de probabilidade.

A análise multivariada aplicada aos dados de concentração de $\mathrm{Na}$ indicou significância estatística, a $5 \%$ de probabilidade, para o efeito dose e tempo, e para as interações tempo $\times$ solo, tempo $\times$ dose, e tempo $\times$ solo $\times$ dose, mas não para a causa de variação solo e a interação solo $\times$ dose. Com relação à dose aplicada, aos 30 dias (Figura 5 A), os maiores valores de Na no lixiviado foram encontrados no Trat. 2, superior à Test, no Argissolo e no Espodossolo. Aos 60 dias (Figura 5 B), não foram encontradas diferenças na concentração de $\mathrm{Na}$ entre os tratamentos, em nenhum dos solos avaliados.

As maiores $(P \leq 0,05)$ concentrações de Na no lixiviado, aos 30 dias de incubação, ocorreram no Argissolo, que não foi diferente do Espodossolo, seguido do Nitossolo, que também não foram diferentes entre si. Aos 60 dias, os maiores valores de $\mathrm{Na}$ no lixiviado foram encontrados no Argissolo, que não foram diferentes do Nitossolo, seguido do Espodossolo, que também não foram diferentes entre si (Figura 5 B).

Os resultados encontrados mostram elevação da concentração de Na nos lixiviados dos solos que receberam aplicações de vinhaça, devido à competição com $\mathrm{K}$ tê-lo expulsado dos sítios de troca dos solos. Além do que, aos 30 dias, o aumento da concentração de Na obedeceu à tendência que, quanto maior a dose aplicada, maior o teor do elemento no lixiviado, nos três solos utilizados, ficando evidenciada, então, a importância da dose a ser aplicada, corroborando as afirmações de CAMBUIM (1983).

Ainda com relação aos teores de Na nos lixiviados dos solos em que foi aplicada a vinhaça, foram menores para o Nitossolo, provavelmente pelos maiores valores da fração argila; no Espodossolo, de forma intermediária pela presença do horizonte espódico e, para o Argissolo, provavelmente, por ter menor fração argila que o Nitossolo. 


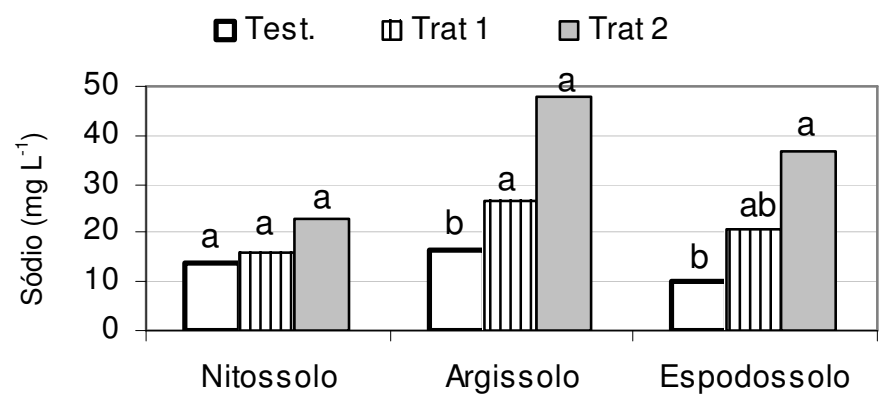

(A)

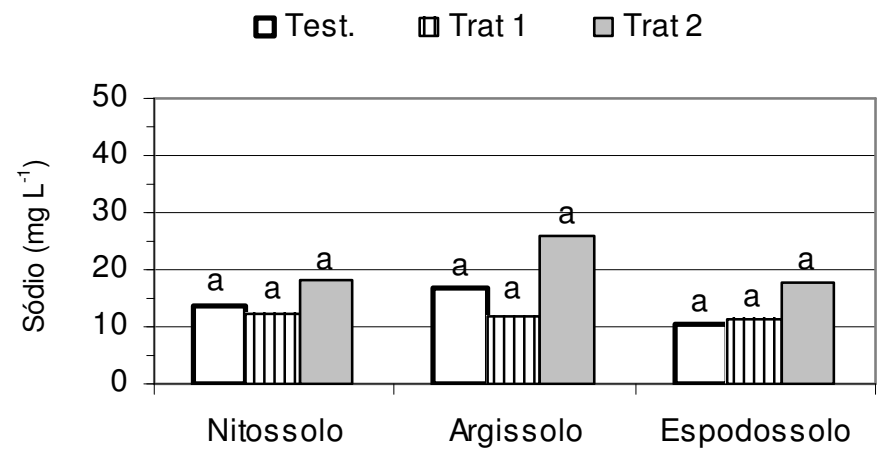

(B)

FIGURA 5. Concentração de Na no lixiviado das colunas dos três tipos de solo, aos 30 (A) e 60 (B) dias após a aplicação de vinhaça; médias de três repetições, seguidas de mesma letra, não diferem pelo teste de Tukey, a 5\% de probabilidade.

De maneira geral, o Nitossolo apresentou concentrações dos elementos químicos estudados significativamente menores que os encontrados no Argissolo, assim como no Espodossolo, indicando elevada capacidade de reter os cátions presentes na vinhaça, o que pode ser facilmente explicado pelo seu maior teor de argila em toda a extensão do perfil (Nitossolo). Contudo, os valores encontrados para o Argissolo e o Espodossolo também foram significativamente menores que as concentrações encontradas na vinhaça in natura, o que indica o elevado poder de retenção dos três solos para os elementos estudados, devendo-se também levar em consideração o fator diluição que ocorrera por conta da aplicação das lâminas de água.

\section{CONCLUSÕES}

$\mathrm{O} \mathrm{K}$ do lixiviado diminuiu significativamente em relação à concentração da vinhaça, obedecendo a uma lógica baseada no maior ou menor teor de argila.

A concentração de $\mathrm{Ca}$ foi menor no lixiviado do Nitossolo, maior no Argissolo e intermediário para o Espodossolo.

A concentração do $\mathrm{Mg}$ apresentou-se sempre baixa, o que provavelmente não traria problemas com os lixiviados.

Apesar da elevação na concentração do $\mathrm{Na}$, todos os solos tiveram elevado poder de retenção desse cátion.

O fator diluição também influenciou nos resultados dos lixiviados.

\section{REFERÊNCIAS}

ALMEIDA, J.R.; RANZAN, I.G.; VALSECCHI, O. L'emploi de la vinasse dans l'agriculture. Piracicaba: ESALQ/USP, 1952. p.63-70 (Boletim, 11) 
BRITO, F.L.; LYRA, M.R.C.; ROLIM, M.M. Efeito da aplicação de vinhaça em colunas de solo: avaliação do poder de remoção de alguns parâmetros. In: CONGRESSO BRASILEIRO DE ENGENHARIA AGRÍCOLA, 32., 2003, Goiânia. Anais... Goiânia: Sociedade Brasileira de Engenharia Agrícola, 2003. 1 CD-ROM.

BRITO, F.L.; ROLIM, M.M. Comportamento do efluente e do solo fertirrigado com vinhaça. Revista Agropecuária Técnica, Areia, v.26, n.1, p.78-88, 2005.

CAMARGO, O.A.; VALADARES, J.M.A.S.; GERALDI, R.N. Características químicas e físicas de solo que recebeu vinhaça por longo tempo. Campinas: Instituto Agronômico de Campinas, 1983. 30 p. (Boletim Técnico, 76).

CAMBUIM, F.A. A ação da vinhaça sobre a retenção de umidade, $\mathrm{pH}$, acidez total, acumulação $e$ lixiviação de nutrientes, em solo arenoso. 1983. 133 f. Dissertação (Mestrado em Ciência do Solo) - Universidade Federal Rural de Pernambuco, Recife, 1983.

CORRÊA M.C.M.; CONSOLINI, F.; CENTURION, J.F. Propriedades químicas de um Latossolo Vermelho Distrófico sob cultivo contínuo de cana-de-açúcar (Saccharum spp.). Acta Scientiarum, Maringá, v.23, n.5, p.1159-63, 2001.

EMBRAPA. EMPRESA BRASILEIRA DE PESQUISA AGROPECUÁRIA. Centro Nacional de Pesquisa de Solos. Manual de métodos de análise de solos. 2.ed. Rio de Janeiro, 1997. 212 p. (Documentos, 1)

EMBRAPA. EMPRESA BRASILEIRA DE PESQUISA AGROPECUÁRIA. Centro Nacional de Pesquisa de Solos. Sistema Brasileiro de Classificação de Solos. Brasília, 1999. 412 p.

LYRA, M.R.C.C. Efeito da vinhaça utilizada na fertirrigação sobre a qualidade de águas subsuperficiais. 2002. 122 f. Dissertação (Mestrado em Ciência do Solo) - Universidade Federal Rural de Pernambuco, Recife, 2002.

MEDINA, C.C.; NEVES, C.S.V.J.; FONSECA, I.C.B.; TORRETI, A.F. Crescimento radicular e produtividade de cana-de-açúcar em função de doses de vinhaça em fertirrigação. Semina: Ciências Agrárias, Londrina, v.23, n.2, p.179-84, 2002.

PAULINO, A.F.; MEDINA, C.C.; ROBAINA, C.R.P.; LAURANI, R.A. Produções agrícola e industrial de cana-de-açúcar submetida a doses de vinhaça. Semina: Ciências Agrárias, Londrina, v.23, n.2, p.145-50, 2002.

RANZANI, G. Conseqüências da aplicação de restilo ao solo. Anais da Escola Superior de Agronomia “Luiz de Queiroz”, Piracicaba, v.12, p.57-68, 1956.

SENGIK, E.; RIBEIRO, A.C.; CONDE, A. R. Efeito da vinhaça em algumas propriedades de amostras de dois solos de Viçosa (MG). Revista Brasileira de Ciência do Solo, Campinas, v.12, n.1, p.11-15, 1988.

XAVIER, L.H. Modelos univariado e multivariado para análise de medidas repetidas e verificação de acurácia por meio de simulação. 2000. 91 f. Dissertação (Mestrado em Estatística e Experimentação Agronômica) - Escola Superior de Agricultura "Luiz de Queiroz", Universidade de São Paulo, Piracicaba, 2000. 